\section{JURNAL EKONOMI EFEKTIF}

ISSN : $2622-8882$, E-ISSN : 2622-9935

Jurnal Ekonomi Efektif, Vol. 4, No. 1, Oktober 2021 @Prodi Manajemen Fakultas Ekonomi Universitas Pamulang

\title{
PENGARUH DISPLAY PRODUK TERHADAP MINAT BELI KONSUMEN PADA PT RAGAM FASHION DI BANDUNG
}

\author{
Ardian Nurrahman', Happy Christman Gulo², Muhamad Fauzan Rahadian³, \\ Muhammad Eko Wahyudi ${ }^{4}$, Dadang kurnia ${ }^{\text {* }}$ \\ Universitas Pamulang, Tangerang Selatan, Banten, Indonesia \\ ardiannurrahman77@gmail.com ${ }^{1}$, happygulo97@gmail.com², \\ fauzanrahadian.rf@gmail.com ${ }^{3}, \underline{\text { ydikentaki@gmail.com }}{ }^{4}, \underline{\text { dosen00188@ }}$ unpam.ac.id ${ }^{5^{*}}$
}

Manuskrip: Agustus -2021; Ditinjau: Agustus -2021; Diterima: September-2021; Online: Oktober-2021; Diterbitkan: Oktober-2021

\begin{abstract}
ABSTRAK
Penelitian ini bertujuan untuk mengetahui pengaruh display produk terhadap minat beli konsumen pada PT. Ragam Fashion di Bandung. Metode yang digunakan adalah explanatory research dengan sampel sebanyak 96 responden. Teknik analisis menggunakan analisis statistik dengan pengujian regresi, korelasi, determinasi dan uji hipotesis. Hasil penelitian ini variabel display produk diperoleh nilai rata-rata skor sebesar 3,414 dengan kriteria baik. Variabel minat beli konsumen diperoleh nilai rata-rata skor sebesar 3,827 dengan kriteria baik. Display produk berpengaruh positif dan signifikan terhadap minat beli konsumen dengan nilai persamaan regresi $\mathrm{Y}=10,431+0,816 \mathrm{X}$, dan nilai koefisien korelasi 0,763 atau memiliki tingkat hubungan yang kuat dengan nilai determinasi 58,2\%. Uji hipotesis diperoleh signifikansi $0,000<0,05$.
\end{abstract}

Kata Kunci: Display Produk, Minat Beli Konsumen

\section{ABSTRACT}

This study aims to determine the effect of product display on consumer buying interest at PT. Variety of Fashion in Bandung. The method used is explanatory research with a sample of 96 respondents. The analysis technique uses statistical analysis with regression, correlation, determination and hypothesis testing. The results of this study showed that the product display variable obtained an average score of 3,414 with good criteria. The variable of consumer buying interest obtained an average score of 3.827 with good criteria. Product display has a positive and significant effect on consumer buying interest with the value of the regression equation $Y=10.431+0.816 X$, and the correlation coefficient value of 0.763 or has a strong relationship with a determination value of $58.2 \%$. Hypothesis testing obtained a significance of $0.000<0.05$.

Keywords: Product Display, Consumer Buying Interest 


\section{PENDAHULUAN}

\section{A. Latar Belakang Masalah}

Perubahan cara memasarkan produk disertai dengan banyaknya ragam media yang dapat digunakan dalam ikut menawarkan produk menjadi tantangan pemasar dalam mengoptimalkan penjualannya. Saat ini perilaku konsumen yang diambil konsumen dalam melaksanakan keputusan untuk membeli barang atau jasa menjadi unik dan memilih cara yang lebih simpel. Maka dari itu perusahaan harus dapat mengambil tindakan yang tepat dalam memotivasi konsumen untuk memenuhi produk yang dihasilkan dan dapat menciptakan keputusan pembelian bagi konsumen. Dalam usaha penataan barang agar konsumen mau berkunjung kembali, maka ada beberapa faktor yang mempengaruhinya diantaranya adalah kualitas hubungan yang baik dengan setiap konsumennya, dan kemampuan perusahaan dalam menangani keluhan dari konsumen. Hubungan ini sendiri dapat menimbulkan keputusan pembelian konsumen dan untuk membangun suatu hubungan yang lebih dekat. Dengan menciptakan komunikasi dua arah sehingga dapat menimbulkan kepercayaan dan keputusan pembelian hingga keputusan pembelian yang dilakukan oleh konsumen.

Bisnis dunia fashion saat ini telah berkembang besar di Indonesia. Mulai dari fashion anak-anak sampai fashion orang dewasa sangat banyak kita jumpai disemua modern market ataupun di department store. Masuknya merek fashion internasional ke Indonesia membuat Indonesia semakin modern dalam dunia fashion, dan produk Indonesiapun tidak kalah dalam persaingan merebut pasar dunia fashion di Indonesia.

Di Indonesia bisnis fashion merek internasional banyak dimonopoli oleh perusahaan besar seperti MAP Group, GAP Group dan sebagainya. Namun produk fashion Indonesia tetap bertahan karena masih sangat banyak dicintai oleh masyarakat Indonesia. Semakin banyaknya mall ataupun modern market yang beroperasional di Indonesia maka semakin banyak pula merek fashion internasional masuk ke Indonesia, sehingga para pengusaha semakin memperketat daya saing agar produk atau merek mereka semakin laku dan diminati dipasaran. Maka untuk brand atau merek produk fashion lokal harus siap menghadapinya dan mampu bersaing.

PT. Ragam Fashion adalah perusahaan retail yang mendistribusikan pakaian sehari-hari dan pakaian tidur untuk semua usia mulai dari anak-anak, dewasa, wanita hingga laki-laki, serta menyediakan berbagai ukuran serta dengan varian merek dan bahan-bahan yang berkualitas. Benvica sleepwear saat ini mempunyai 15 toko yang tersebar di Jabodetabek, dari semua toko yang dimiliki oleh benvica terdapat beberapa toko yang penjualannya mengalami penurunan dan tidak sampai dengan target yang telah ditetapkan oleh manajemen PT. Ragam Fashion.

Dalam operasionalnya benvica memiliki cara tersendiri yang dapat menarik minat konsumen atau pembeli agar mau memakai atau membeli produknya, untuk itu para pramugiana atau SPG (Sales Promotion Girl) harus diberikan pengajaran atau ilmu yang baik dalam melaksanakan opersional, seperti tehnik pendisplayan atau penataan barang. Permasalahan yang sering terjadi adalah kurang berminatnya konsumen atau konsumen untuk memiliki barang yang kita jual dikarenakan permasalahan- permasalahan yang seharusnya bisa dihindari agar konsumen tertarik untuk membeli produk kita tersebut.

Untuk menarik konsumen agar tertarik masuk dan membeli maka hal yang pertama harus diperhatikan adalah display produk. Menurut Sopiah dan Syiahbudhin (2008) display adalah usaha yang dilakukan untuk menata barang yang mengarahkan pembeli agar tertarik untuk melihat dan membeli. Display barang sangat penting dilakukan, Karena display yang baik akan menimbulkan minat konsumen untuk membelinya Permasalahan yang dibahas disini adalah display produk yang belum 
optimal dikarenakan lokasi dan ukuran toko yang sangat kecil sehingga sulit untuk memaksimalkan dalam pendisplayan, oleh karena itu maka harus menggunakan tehnik dalam pendisplayan agar dapat terlihat lebih menarik dan untuk menciptakan keputusan pembelian bagi konsumen yang melihatnya.Menurut Kotler dan Keller (2009: 240) keputusan pembelian adalah keputusan para konsumen membentuk preferensi atas merek-merek yang ada dalam kumpulan pilihan, konsumen tersebut juga dapat membentuk niat untuk membeli merek yang paling disukai.

Berdasarkan latar belakang permasalahan diatas maka penulis tertarik untuk melakukan penelitian mengenai, "Pengaruh Display Produk Terhadap Keputusan Pembelian di PT. Ragam Fashion Asih Bekasi".

\section{B. Rumusan Masalah}

1. Bagaimana display produk pada PT. Ragam Fashion di Bandung ?.

2. Bagaimana minat beli konsumen pada PT. Ragam Fashion di Bandung ?.

3. Adakah pengaruh antara display produk terhadap minat beli konsumen pada PT. Ragam Fashion di Bandung?.

\section{Tujuan Penelitian}

1. Untuk mengetahui kondisi display produk pada PT. Ragam Fashion di Bandung.

2. Untuk mengetahui kondisi minat beli konsumen pada PT. Ragam Fashion di Bandung.

3. Untuk mengetahui pengaruh display produk terhadap minat beli konsumen pada PT. Ragam Fashion di Bandung.

\section{TINJAUAN PUSTAKA}

\section{Display produk}

Menurut Kotler dalam Tjiptono (2019) menyatakan bahwa "Display produk adalah tingkat keunggulan yang diharapkan dan pengendalian atas tingkat keunggulan tersebut untuk memenuhi keinginan konsumen".

\section{Minat beli konsumen}

Menurut Kotler dan Amstrong (2019) berpendapat "perilaku konsumen merupakan sebuah pendekatan penyesuaian masalah yang terdiri dari lima tahap yang dilakukan konsumen. Kelima tahap tersebut adalah pengenalan masalah, pencarian informasi, evaluasi alternatif, minat beli konsumen, dan perilaku pasca pembelian".

\section{METODE PENELITIAN}

\section{Populasi}

Yang dijadikan sebagai populasi dalam penelitian ini adalah responden yang berjumlah 96 responden PT. Ragam Fashion di Bandung

\section{Sampel}

Teknik pengambilan sampling dalam penelitian ini adalah sampel jenuh, dimana semua anggota populasi dijadikan sebagai sampel. Dengan demikian sampel dalam penelitian ini sampel yang digunakan berjumlah 96 responden.

\section{Jenis Penelitian}

Jenis penelitian yang dipakai adalah kuantitatif, dimana tujuannya adalah untuk mengetahui atau mencari keterhubungan antara variabel independen terhadap variabel dependennya

\section{Metode Analisis Data}

Dalam menganalisis data digunakan uji validitas, uji reliabilitas, analisis regresi 
linier sederhana, analisis koefisien korelasi, analisis koefisien determinasi dan pengujian hipotesis.

\section{HASIL PENELITIAN}

\section{Analisis Deskriptif}

Pada pengujian ini digunakan untuk mengetahui skor minimum dan maksimum skor tertinggi, ratting score dan standar deviasi dari masing-masing variabel. Adapun hasilnya sebagai berikut:

Tabel 1. Hasil Analisis Descriptive Statistics

Descriptive Statistics

\begin{tabular}{lr|r|r|r|r} 
& N & Minimum & Maximum & Mean & Std. Deviation \\
\hline Display produk (X) & 96 & 28 & 44 & 34.14 & 3.917 \\
\hline Minat beli konsumen (Y) & 96 & 29 & 49 & 38.27 & 4.186 \\
\hline Valid N (listwise) & 96 & & & & \\
\hline
\end{tabular}

Display produk diperoleh varians minimum sebesar 28 dan varians maximum 44 dengan ratting score sebesar 3,414 dengan standar deviasi 3,917. Skor ini termasuk pada rentang sakala 3,40-4,19 dengan kriteria baik atau setuju.

Minat beli konsumen diperoleh varians minimum sebesar 29 dan varians maximum 49 dengan ratting score sebesar 3,827 dengan standar deviasi 4,186. Skor ini termasuk pada rentang sakala 3,40 - 4,19 dengan kriteria baik atau setuju.

\section{Analisis Kuantitatif}

Pada analisis ini dimaksudkan untuk mengetahui pengaruh variabel independen terhadap variabel dependen. Adapun hasil pengujian sebagai berikut:

\section{a. Analisis Regresi Linier Sederhana}

Uji regresi ini dimaksudkan untuk mengetahui perubahan variabel dependen jika variabel independen mengalami perubahan. Adapun hasil pengujiannya sebagai berikut:

\begin{tabular}{|c|c|c|c|c|c|}
\hline \multirow[b]{3}{*}{ Model } & \multicolumn{3}{|c|}{ Coefficients $^{\mathrm{a}}$} & \multirow[b]{3}{*}{$\mathrm{t}$} & \multirow[b]{3}{*}{ Sig. } \\
\hline & \multicolumn{2}{|c|}{$\begin{array}{l}\text { Unstandardized } \\
\text { Coefficients }\end{array}$} & \multirow{2}{*}{$\begin{array}{c}\text { Standardized } \\
\text { Coefficients } \\
\text { Beta } \\
\end{array}$} & & \\
\hline & $\mathrm{B}$ & Std. Error & & & \\
\hline 1 (Constant) & 10.431 & 2.448 & & 4.260 & .000 \\
\hline Display produk (X) & .816 & .071 & .763 & 11.444 & .000 \\
\hline
\end{tabular}

Berdasarkan hasil pengujian pada tabel di atas, diperoleh persamaan regresi $\mathrm{Y}$ $=10,431+0,816 \mathrm{X}$. Dari persamaan tersebut dijelaskan sebagai berikut:

1) Konstanta sebesar 10,431 diartikan jika display produk tidak ada, maka telah terdapat nilai minat beli konsumen sebesar 10,431 point.

2) Koefisien regresi display produk sebesar 0,816, angka ini positif artinya setiap ada peningkatan display produk sebesar 0,816 point maka minat beli konsumen juga akan mengalami peningkatan sebesar 0,816 point.

\section{b. Analisis Koefisien Korelasi}

Analisis koefisien korelasi dimaksudkan untuk mengetahui tingkat kekuatan hubungan dari variabel independen terhadap variabel dependen. Adapun hasil pengujian sebagai berikut: 
Tabel 3. Hasil Pengujian Koefisien Korelasi Display produk Terhadap Minat beli konsumen.

Correlations $^{b}$

\begin{tabular}{ll|r|r} 
& & $\begin{array}{r}\text { Display produk } \\
\text { (X1) }\end{array}$ & \multicolumn{1}{c}{$\begin{array}{c}\text { Minat beli } \\
\text { konsumen (Y) }\end{array}$} \\
\hline Display produk (X) & Pearson Correlation & 1 & $.763^{* *}$ \\
\cline { 2 - 4 } & Sig. (2-tailed) & & .000 \\
\hline Minat beli konsumen (Y) & Pearson Correlation & $.763^{* *}$ & 1 \\
\cline { 2 - 4 } & Sig. (2-tailed) & .000 & \\
\hline
\end{tabular}

Berdasarkan hasil pengujian diperoleh nilai korelasi sebesar 0,763 artinya display produk memiliki hubungan yang kuat terhadap minat beli konsumen.

\section{c. Analisis Koefisien Determinasi}

Analisis koefisien determinasi dimaksudkan untuk mengetahui besarnya persentase pengaruh dari variabel independen terhadap variabel dependen. Adapun hasil pengujian sebagai berikut:

Tabel 4. Hasil Pengujian Koefisien Determinasi Display produk Terhadap Minat beli konsumen.

Model Summary

\begin{tabular}{|c|c|c|c|c|}
\hline \multicolumn{5}{|c|}{ Model Summary } \\
\hline Model & $\mathrm{R}$ & R Square & $\begin{array}{l}\text { Adjusted R } \\
\text { Square }\end{array}$ & $\begin{array}{l}\text { Std. Error of the } \\
\text { Estimate }\end{array}$ \\
\hline 1 & $.763^{\mathrm{a}}$ & .58 & .5 & 2.720 \\
\hline
\end{tabular}

Berdasarkan hasil pengujian diperoleh nilai determinasi sebesar 0,582 artinya display produk memiliki kontribusi pengaruh sebesar $58,2 \%$ terhadap minat beli konsumen, sedangkan sisanya sebesar $41,8 \%$ dipengaruhi oleh faktor lain yang tidak dilakukan penelitian.

\section{d. Uji Hipotesis}

Pengujian hipotesis dengan uji t digunakan untuk mengetahui hipotesis mana yang diterima.

Rumusan hipotesis: Terdapat pengaruh yang signifikan display produk terhadap minat beli konsumen.

Tabel 5. Hasil Uji Hipotesis Display produk Terhadap Minat beli konsumen.

\section{Coefficients $^{\mathrm{a}}$}

Unstandardized

Coefficients

\begin{tabular}{|c|c|c|c|c|c|}
\hline \multirow[b]{2}{*}{ Model } & \multicolumn{2}{|c|}{ Coefficients } & \multirow{2}{*}{$\begin{array}{c}\text { Coefficients } \\
\text { Beta }\end{array}$} & \multirow[b]{2}{*}{$\mathrm{l}$} & \multirow[b]{2}{*}{ Sig. } \\
\hline & $\mathrm{B}$ & Std. Error & & & \\
\hline 1 (Constant) & 10.431 & 2.448 & & 4.260 & .000 \\
\hline Display produk (X) & .816 & .071 & .763 & 11.444 & .000 \\
\hline
\end{tabular}

Berdasarkan hasil pengujian pada tabel di atas, diperoleh nilai t hitung $>\mathrm{t}$ tabel atau $(11,444>1,986)$, dengan demikian hipotesis yang diajukan bahwa terdapat pengaruh yang signifikan atara display produk terhadap minat beli konsumen diterima.

\section{Pembahasan Hasil Penelitian}

\section{Kondisi Jawaban Responden Variabel Display produk}

Berdasarkan jawaban responden, variabel display produk diperoleh ratting score sebesar 3,414 berada di rentang skala 3,40-4,19 dengan kriteria baik atau setuju.

\section{Kondisi Jawaban Responden Variabel Minat beli konsumen}

Berdasarkan jawaban responden, variabel minat beli konsumen diperoleh ratting 
score sebesar 3,827 berada di rentang skala 3,40 - 4,19 dengan kriteria baik atau setuju.

\section{Pengaruh Display produk Terhadap Minat beli konsumen}

Display produk berpengaruh signifikan terhadap minat beli konsumen dengan persamaan regresi $\mathrm{Y}=10,431+0,816 \mathrm{X}$, nilai korelasi sebesar 0,763 atau memiliki hubungan yang kuat dengan kontribusi pengaruh sebesar 58,2\%. Pengujian hipotesis diperoleh nilai t hitung $>\mathrm{t}$ tabel atau $(11,444>1,986)$. Dengan demikian hipotesis yang diajukan bahwa terdapat berpengaruh signifikan antara display produk terhadap minat beli konsumen diterima.

\section{KESIMPULAN DAN SARAN}

\section{Kesimpulan}

a. Variabel display produk diperoleh ratting score sebesar 3,414 berada di rentang skala 3,40 - 4,19 dengan kriteria baik atau setuju.

b. Variabel minat beli konsumen diperoleh ratting score sebesar 3,827 berada di rentang skala 3,40-4,19 dengan kriteria baik atau setuju.

c. Display produk berpengaruh signifikan terhadap minat beli konsumen dengan persamaan regresi $\mathrm{Y}=10,431+0,816 \mathrm{X}$, nilai korelasi sebesar 0,763 atau kuat dan kontribusi pengaruh sebesar 58,2\% sedangkan sisanya sebesar $41,8 \%$ dipengaruhi faktor lain. Uji hipotesis diperoleh nilai $t$ hitung $>t$ tabel atau $(11,444>1,986)$.

\section{Saran} berikut:

Berdasarkan hasil penelitian di atas, maka penulis memberikan saran sebagai

a. Perusahaan harus lebih meningkatkan kembali teknik display agar lebih kreatif dan inovatif sehingga dapat lebih menarik perhatian konsumen agar melakukan pembelian.

b. Perusahaan sebaiknya memberikan informasi yang lebih tentang produk yang dijual dikarenakan masih banyak konsumen yang mencari tahu sendiri tentang informasi produk yang akan dibeli, dan akan sangat membatu proses keputusan pembelian jika perusahaan memberikan secara detail dan jelas tentang infromasi produknya.

c. Perusahaan sebaiknya menyewa toko yang lebih besar lagi dari toko yang sekarang karena untuk memaksimalkan dalam pendisplayan produk yang dijual agar lebih terhihat menarik dan membuat konsumen nyaman dalam berbelanja.

\section{DAFTAR PUSTAKA}

Abdullah, M (2014) Manajemen dan Evaluasi Keputusan pembelian, Yogyakarta: Penerbit Aswaja Pressindo.

Algifari. (2015). "Analisis Regresi untuk Bisnis dan Ekonomi”. Yogyakarta: BPFE.

Ardani, W., Khan, A. H., Noviyanti, I., \& Khan, M. F. Z. (2020). The Effect of Private Visiting and Promotion Strategy on Tourist Interest Visiting in Bali City. International Journal of Educational Administration, Management, and Leadership, 27-38.

Arikunto, Suharsimi (2014). “Prosedur Penelitian Suatu Pendekatan Praktek”. Bandung: Rineka Cipta.

Bashu Swastha dan T. Handoko (2015) Manajemen Pemasaran Moderen, Yogyakarta: BPFE.

Basu Swastha Dharmmesta. (2014). Manajemen Pemasaran. BPFE: Yogyakarta.

Buchari Alma. 2014. Manajemen pemasaran dan Pemasaran Jasa. Edisi Revisi. 
Bilson Simamora (2016) Panduan Riset Prilaku Konsumen, Bandung: PT. Gramedia Pustaka.

Fandy Tjiptono (2017), Serivce Quality and Satisfiation. Bandung: Edisi tiga. Andi.

Freddy Rangkuti (2016) Strategi Promosi Yang Kreatif, Edisi Pertama, Cetakan Pertama Bandung: Gramedia Pustaka Utama.

Imam Ghozali (2017). “Aplikasi Analisis Multivariate Dengan Program SPSS”. Edisi Kelima. Semarang: Badan Penerbit Undip.

Istijanto (2014) “Riset Sumber Daya Manusia”. Bandung: PT. Gramedia Pustaka

Jasmani, J. (2018). Pengaruh Kualitas Produk Dan Harga Terhadap Keputusan Pembelian Pada PT. Baja Mandiri Di Bandung. Disrupsi Binis, 1(1).

Jasmani, J., \& Sunarsi, D. (2020). The Influence of Product Mix, Promotion Mix and Brand Image on Consumer Purchasing Decisions of Sari Roti Products in South Tangerang. PINISI Discretion Review, 1(1), 165-174.

Kharis, Ismu Fadli (2011). "Studi Mengenai Impulse Buying dalam Penjualan Online”. Semarang : Skripsi Universitas Diponegoro

Kotler dan Amstrong (2017), Prinsip-prinsip Pemasaran. Edisi Kedua Belas”. Jilid Satu. Bandung: Erlangga.

Lupiyoadi (2016) Manajemen Pemasaran Jasa, Edisi 4, Bandung: Salemba Empat.

Maddinsyah, A., et al. (2020). Desain Formulasi Dan Implementasi Bisnis Strategik Dengan Pendekatan Business Model Canvas (BMC) Terintegrasi Kerangka Integrated Performance Management System (IPMS) Pada Koperasi Asperindo. Inovasi, 7(2), 67-76.

Nurjaya, N., et al. (2021). Pengaruh Brand Image Terhadap Keputusan Pembelian Pada PT. Wahana Motor Di Wilayah Cianjur. Jurnal IImiah PERKUSI, 1(2), 291-296.

Philip Kotler (2017) Manajemen Pemasaran, Edisi Keempat Belas, Bandung: PT. Indeks. Phipil Kotler dan Kevin Keller (2017) Manajemen Pemasaran, Edisi Kedua Belas, Jilid Satu, Bandung: Erlangga.

Rao, Purba, (2012). "Measuring Consumer Perceptions Through Factor Analysis", The Asian.

Rofianto, W., et al. (2021). Cultural Product Branding, Antecedents, And Its Implications: A Study On The Context Of Indonesian Batik. International Journal Of Social, Policy And Law, 2(2), 37-46.

Santoso, Singgih (2015). "Menguasai Statistik Multivariat”. Bandung: PT Elex Media Komputindo.

Sudjana (2014) “Metode Statistika”, Bandung: Tarsido.

Sugiyono (2017), "Metode Penelitian Administrasi : dilengkapi dengan Metode $R \&$ D”. Bandung: Alfabeta.

Suhartanto (2014). "Metode Riset Pemasaran". Bandung: Alfabeta

Wangsi, M. M., et al. (2018). Perlindungan Konsumen Dalam Pelabelan Produk Menurut Ekonomi Islam. Sentralisasi, 7(1), 1-9. 